\title{
APLIKASI PENGENALAN NAMA-NAMA HEWAN
}

\author{
Agus Darmawan \\ Program Studi Informatika, Universitas Indraprasta PGRI \\ Email: agus.darmawan@unindra.ac.id
}

\begin{abstract}
Abstrak
Kemunculan teknologi sudah memperlihatkan dampak yang signifikan yaitu perubahan pola manusia. Baik itu merupakan dampak hal negatif maupun positif dari pengunaan smartphone. Dilihat dari dampak pengunan smartphone ternyata memberikan dampak positif juga jika di gunakan sebagai media pembelajaran. Gabungan antara teknologi dan media pembelajaran baru yang sangat di butuhkan oleh sekolah Taman kanak-kanak yang dapat membantu pengajar dalam menyampaikan materi tentang kosakata mengenal Nama-nama Hewan. Dalam meracangan aplikasi media pembelajaran mengenal nama-nama hewan dibuat menggunakan metode pengerjaan dengan waterfall dan dibantu dengan bahasa pemrograman java android dengan target luaran yang akan dicapai dari perancangan ini adalah purwarupa berupa aplikasi mengenal nama-nama hewan dalam bentuk media pembelajaran pada TK NEGERI JAGAKARSA 01 berbasis android. Dengan adanya aplikasi ini diharapkan dapat membantu pengajar dalam memanfaatkan media pembelajar untuk meningkatkan kemampuan siswa dalam menyerap materi yang di berikan oleh guru.
\end{abstract}

Kata Kunci : media pembelajaran, nama hewan, waterfall, Smartphone, dan android.

\begin{abstract}
The emergence of technology has shown a significant impact on changing human patterns. Whether it's a negative or positive impact on the use of smartphones. Judging from the impact of using a smartphone, it turns out to have a positive effect if used as a learning medium. A combination of technology and new learning media that are needed by kindergarten schools that can help teachers deliver material on vocabulary to know the names of animals. In designing learning media applications to know the names of animals created using the method of working with waterfall and assisted with the java android programming language with the target output that will be achieved from this design is a prototype in the form of an application to recognize the names of animals in the form of learning media in TK NEGERI JAGAKARSA 01 Android-based. With this application, it is expected to be able to assist teachers in utilizing learning media to improve students' ability to absorb material given by the teacher.
\end{abstract}

Key Words : waterfall, smartphone, kindergarten, android java

\section{PENDAHULUAN}

Kemunculan teknologi sudah memperlihatkan dampak yang signifikan yaitu perubahan pola manusia. Baik itu merupakan dampak hal negatif maupun positif dari pengunaan smartphone.

Dampak dari teknologi Smartphone tentu berpengaruh di berbagai bidang kehidupan seperti ekonomi, sosial, budaya, ataupun pendidikan. Terutama di bidang pendidikan yang sekarang sudah diwarnai dengan pengaruh globalisasi. Salah satu perkembangan teknologi yang sangat pesat dan digunakan sebagai media pembelajaran adalah smartphone.

Dalam pengertian sebuah media adalah semua bentuk perantara yang digunakan media. Secara lebih khusus, pengertian media dalam proses pembelajara yang dapat di terapkan kedalam teknologi seperti smartphone [1] .

Smartphone (ponsel cerdas) "merupakan salah satu wujud realisasi uquitous computing (ubicomp) di mana teknologi tersebut memungkinkan proses komputasi dapat terintegrasi dengan 
berbagai aktifitas keseharian manusia dengan jangkauannya yang tidak dibatasi dalam satu wilayah atau suatu scope area" [2].

Smartphone dapat dipandang sebagai suatu sebagai suatu sistem yang dikembangkan dalam upaya peningkatan kualitas pembelajaran dengan berupaya menembus keterbatasan ruang dan waktu, maka smartphone ini dapat di katakan sebagai alat trobosan baru dalam penyampaian Informasi media pembelajaran [3].

Terlepas dari efek-efek negatif smartphone yang dapat memberikan dampak positif untuk anak jika di pergunakan secara tepat. Penggunan secara tepat dimaksudkan untuk mempertimbangkan usia anak pada saat pemberian smartphone. Sebelum dibekali dengan smartphone ,anak sebaiknya dibekali pengetahuan dasar dahulu, jika smartphone adalah media belajar sekunder, yaitu media yang hanya digunakan sebagai pelengkap dan pendamping pada proses belajar anak.

Dalam dunia mengajar terdapat dua aspek yang sangat penting yaitu sebuah metode pembelajaran dan sebuah media pembelajaran sebagai alat bantu dalam mengajar sehigga membantu memudahkan dalam melakukan transfer ilmu ke siswa [4].

Proses belajar pada anak, khususnya belajar mengenal hewan tradisional mudah melalui animasi yang menarik, seperti hal diajarkan oleh guru, orang tua, tutor dan lain-lain[4].

Berdasarkan permasalahan tersebut dibutuhkan aplikasi smartphone dengan mengutamakan usur pembelajaran menarik dengan smartphone seperti belajar mengenal hewan dan buah yang dapat meningkat antusias siswa terhadap media belajar baru serta dapat membantu para pengajar dalam pemanfaatan kemajuan teknologi untuk meningkatkan daya kreatifitas anak dan diimbangi dengan interaksi anak terhadap lingkungan sekitarnya. Sehingga pengajar dapat menggunakan media pelajaran baru yang bisa di terapakan di TK NEGERI JAGAKARSA 01.

\section{METODE}

Dalam melakukan penelitian diperlukan suatu metode supaya dapat menemukan solusi dalam masalah penelitian yang akan diteliti. Metode penelitian adalah suatu teknik atau cara mencari, memperoleh, mengumpulkan atau mencatat data yang dapat digunakan untuk faktor-faktor yang berhubungan dengan pokok permasalahan, sehingga akan dapat suatu kebenaran atas data yang diperoleh. Peneliti menggunakan metode Waterfall yaitu siklus hidup klasik (classic life cycle) yang bersifat sistematis, berurutan dalam membangun suatu software". [5]

Dimana hal ini menggambarkan pendekatan yang sistematis dan juga berurutan pada pengembangan perangkat lunak, dimulai dengan spesifikasi kebutuhan pengguna lalu berlanjut melalui tahapan-tahapan perencanaan (planning), permodelan (modeling), konstruksi (construction), serta penyerahan sistem ke para pengguna (deployment), yang diakhiri dengan dukungan pada perangkat lunak lengkap yang dihasilkan.

\section{A. Langkah-langkah dalam Waterfall}

Langkah-langkah pokok yang digunakan pada metode ini yaitu anaslisa kebutuhan seperti mengumpulkan data, perancangan sistem, penulisan program, pengujian dan perawatan sistem.

1. Pengumpulan Data

Mengumpulkan kebutuhan secara lengkap kemudian dianalisis dan didefinisikan kebutuhan yang harus dipenuhi oleh program yang akan 
dibangun. Fase ini harus dikerjakan secara lengkap untuk bisa menghasilkan desain yang lengkap.

a. Perancangan Sistem: Perancangan sistem dikerjakan setelah kebutuhan selesai dikumpulkan secara lengkap.

b. Penulisan Program: Desain program diterjemahkan ke dalam kode-kode dengan menggunakan bahasa pemrograman yang sudah ditentukan. Program yang dibangun langsung diuji baik secara unit.

c. Pengujian: Penyatuan unit-unit program kemudian diuji secara keseluruhan.

d. Perawatan Sistem: Mengoperasikan program dilingkungannya dan melakukan pemeliharaan, seperti penyesuaian atau perubahan karena adaptasi dengan situasi sebenarnya.

\section{HASIL DAN PEMBAHASAN}

\section{A. Definisi Masalah Dan Penyelesain}

1. Masalah

Dalam dunia, smartphone memiliki dampak negatif maupun positif. Efekefek negatif dari smartphone dapat memberikan dampak buruk bagi anak. Sehingga perlunya penggunaan smartphone kearah yang berdampak positif seperti media pembelajaran.

2. Penyelesaian Masalah

Dalam masalah di atas maka penulis ingin membuat pembelajaran tentang pengenalan nama hewan sebagai media pembelajar untuk memaafkan kegunaan semartphone sebagai dampak positif. Penulis membuatan aplikasi ini ditekankan konsep sistem yang Use Friendly Interface, karena kemudahan dalam menggunakan aplikasi ini akan menjadi faktor awal dalam membantu guru dalam media pembelajar di TK.

Perancangan aplikasi edukasi pengenalan hewan berbasis android untuk menganalisis data yang diperoleh dalam penulisan artikel ini menggunakan metode deskriptif yaitu metode dengan menyusun data yang diperoleh kemudian diinterpretasikan dan dianalisis sehingga memberikan informasi bagi pemecahan masalah yang dihadapi. Tujuan yang ingin dicapai dengan analisis data ini adalah untuk menyederhanakan data ke dalam bentuk yang dapat di mengerti dan ditafsirkan, sehingga hubungan-hubungan yang ada dalam variable dapat dipelajari dan diuji.

1. Tinjauan Umum Aplikasi

Perancangan aplikasi edukasi pengenalan hewan berbasis android merupakan bentuk implementasi menggunakan device android yang diperuntukkan untuk anak-anak dalam masa kegiatan belajar agar dapat lebih mudah mempelajarinya tanpa harus membeli buku atau mencari di Internet sehingga membuat waktu belajar menjadi kurang.

Aplikasi dibangun menggunakan Android Studio, Software SDK dan $J D K$. karena software tersebut memang biasa digunakan untuk membuat objek/benda dalam komputer dan bersifat Open Source atau terbuka untuk dikembangkan.

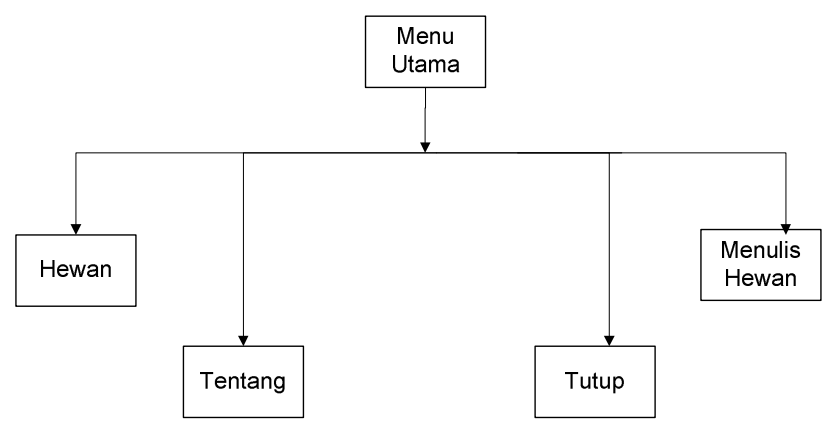

Gambar 1. Struktur Navigasi 
B. Algoritma Penyelesaian Masalah

Dengan Flowchart Dan Pseudocode

1. Menu Utama

a. Flowchart Menu Utama

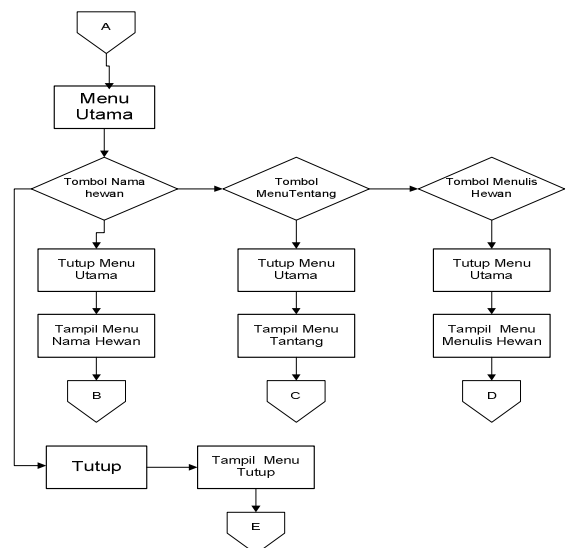

\section{Gambar 2. Flowchart Menu Utama}

b. Penjelasan Pseudocode Menu Utama Pada saat aplikasi sudah masuk menu utama, terdapat tiga tombol yang tersedia. Ketika tombol nama hewan ditekan maka aplikasi akan mengarahkan ke tampilan menu Nama_hewan, kemudian apabila menekan tombol tentang maka aplikasi akan mengarahkan ke tampilan menu tentang. Saat tombol menulis Hewan ditekan maka aplikasi akan mengarahkan ke menu tampilan menulis hewan. dan jika pengguna menekan tombol tutup maka aplikasi akan mengarahkan menu tutup.

2. Menu Nama Hewan

a. Flowchart Menu Nama Hewan

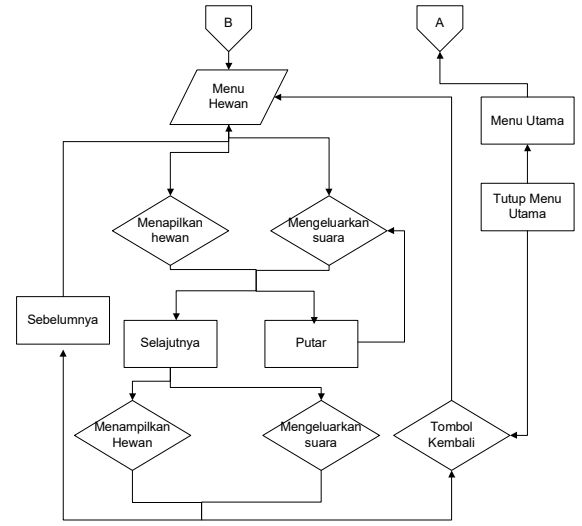

Gambar 3. Flowchart Nama Hewan

b. Penjelasan Pseudocode Nama Hewan
Pada saat aplikasi sudah masuk menu nama Hewan, maka akan tampil nama Hewan yang disertai gambar dan suara. Untuk memutar kembali suara dari Nama Hewan dan gambar silahkan pilih tombol putar, untuk berpindah ke Nama Hewan selanjutnya silahkan pilih tombol selanjutnya dan untuk kembali ke Nama Hewan sebelumnya silahkan pilih tombol sebelumnya.

3. Menu Tentang

a. Flowchart Menu Tentang

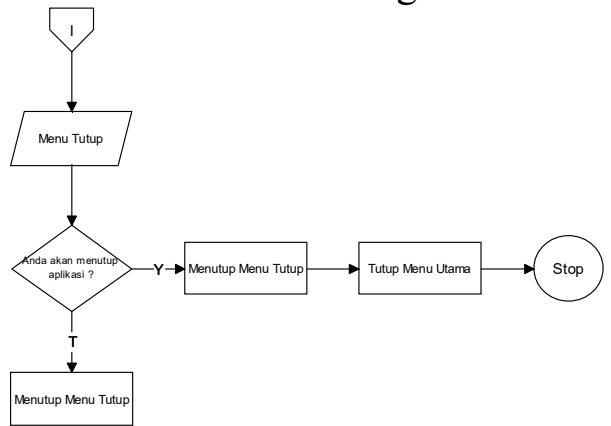

Gambar 4. Flowchart Tentang

b. Penjelasan Pseudocode Tentang

Pada saat aplikasi sudah masuk menu tentang, maka akan tampil tentang dan jika menekan tombol kembali, menu tentang akan menutup dan mengarahkan ke menu utama.

\section{Menu Menulis Hewan}

a. Flowchart Menu Menulis Hewan

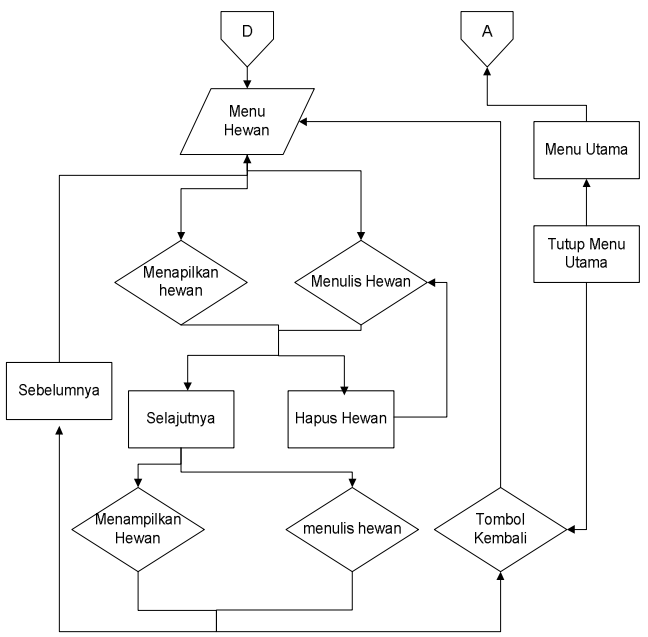

Gambar 5. Flowchart Menu Menulis Hewan 
b. Penjelasan Pseudocode Menu Utama

Pada saat aplikasi sudah masuk menu Menulis Nama hewan, maka akan tampil Nama Hewan yang akan di tulis. di sini anda bisa menuliskan Nama Hewan sesuai yang di tampilkan. Untuk menghapus tulisan huruf yang sudah di tulis silahkan pilih tombol hapus, untuk berpindah ke Nama Hewan selanjutnya silahkan pilih selanjutnya selanjutnya dan untuk kembali ke Nama Hewan sebelumnya silahkan pilih tombol sebelumnya.

\section{Menu Tutup}

a. Flowchart Menu Tutup

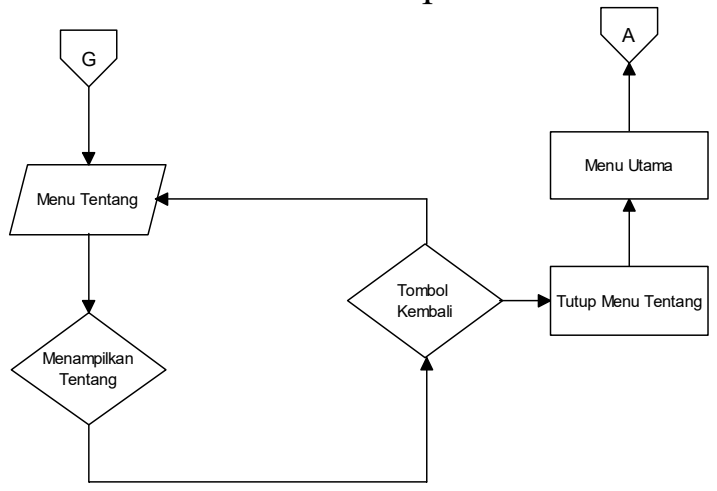

\section{Gambar 6. Flowchart Menu Tutup}

b. Penjelasan Pseudocode Menu Utama Tampilan menu tutup, jika pengguna memilih ya, maka akan menutup menu tutup dan menu utama yang selanjutnya aplikasi akan berhenti.

Apabila memilih tidak maka akan kembali ke menu utama.

\section{Definisi Masalah Dan Penyelesain}

Uji program bertujuan untuk mengetahui aplikasi dapat berjalan baik pada versi yang berbeda dan memiliki tampilan yang cocok terhadap tipe layar yang berbeda-beda. Dibawah ini adalah tampilan program saat penulis mencoba di handphone android Vivo 9 dan Samsung S9+

\section{Menu Utama}

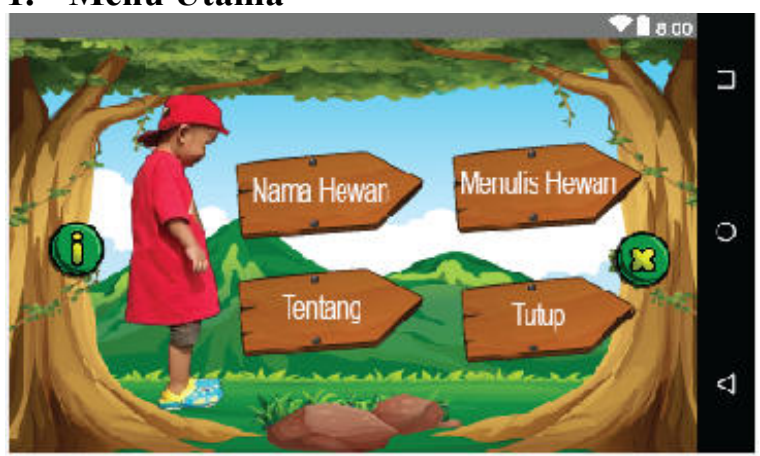

Gambar 7. Tampilan Menu Utama

Gambar 7 adalah tampilan dari menu utama, dimana pada saat aplikasi sudah masuk menu utama, terdapat empat tombol yang tersedia. Ketika tombol nama hewan ditekan maka aplikasi akan mengarahkan ke tampilan menu nama hewan, kemudian apabila menekan tombol tentang maka aplikasi akan mengarahkan tampilan menu tentang. Saat tombol menulis hewan ditekan maka aplikasi akan mengarahkan ke menu tampilan menulis hewan, dan jika pengguna menekan tombol tutup maka aplikasi akan keluar atau menutup.

\section{Menu Nama Hewan}

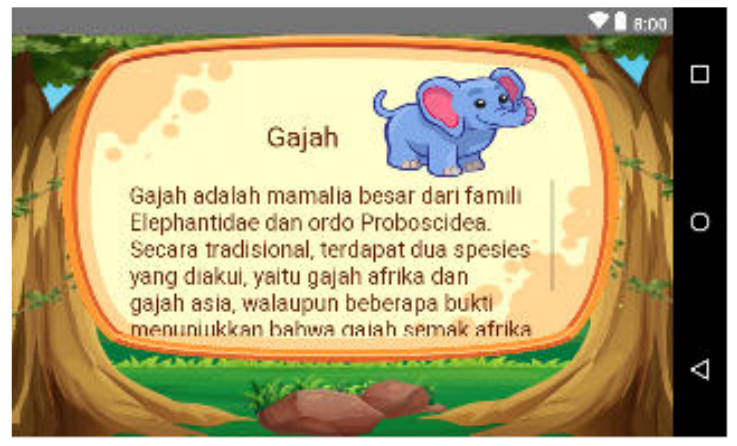

Gambar 8. Tampilan Menu Nama Hewan

Gambar 8 adalah tampilan dari menu nama hewan, dimana Pada saat aplikasi sudah masuk menu nama hewan, maka akan tampil nama hewan yang disertai gambar dan suara. Untuk memutar kembali suara dari hewan dan gambar silahkan pilih tombol putar, untuk berpindah ke hewan selanjutnya silahkan pilih tombol selanjutnya dan untuk kembali ke hewan sebelumnya silahkan pilih tombol sebelumnya. 


\section{Menu menulis Hewan}

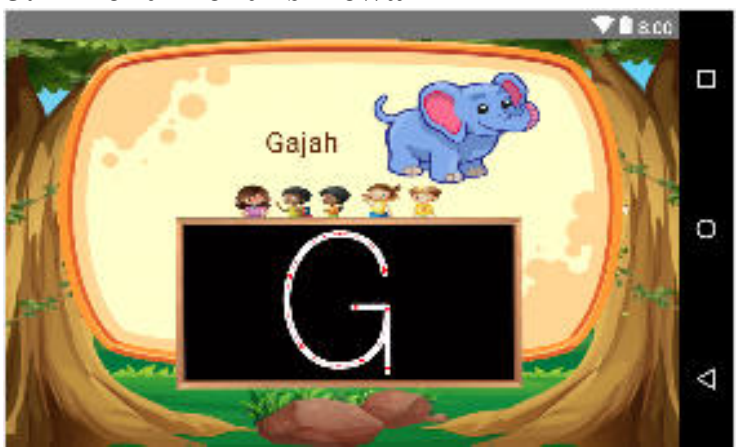

Gambar 9. Tampilan Menu Menulis Hewan

Gambar 9 adalah tampilan menu petunjuk, dimana Pada saat aplikasi sudah masuk menu Menulis Hewan, maka akan tampil hewan alphabet yang akan di tulis. di sini anda bisa menuliskan hewan sesuai yang di tampilkan. Untuk menghapus tulisan hewan yang sudah di tulis silahkan pilih tombol hapus, untuk berpindah ke hewan selanjutnya silahkan pilih selanjutnya selanjutnya dan untuk kembali ke hewan sebelumnya silahkan pilih tombol sebelumnya.

\section{Menu Tentang}

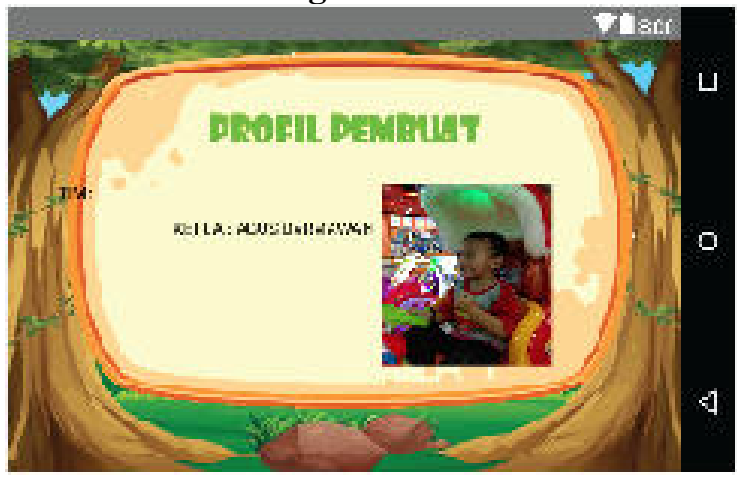

Gambar 10. Tampilan Menu Tentang

Gambar 10 adalah tampilan tentang, dimana Pada saat aplikasi sudah masuk menu tentang, maka akan tampil tentang yang akan mengetahui tentang pembuat. Di sini anda bisa melihat nama, npm dan jurusan pembuat sesuai yang di tampilkan. Terdapat juga tombol kembali yang digunakan untuk kembali ke menu utama.

\section{Menu Tutup}

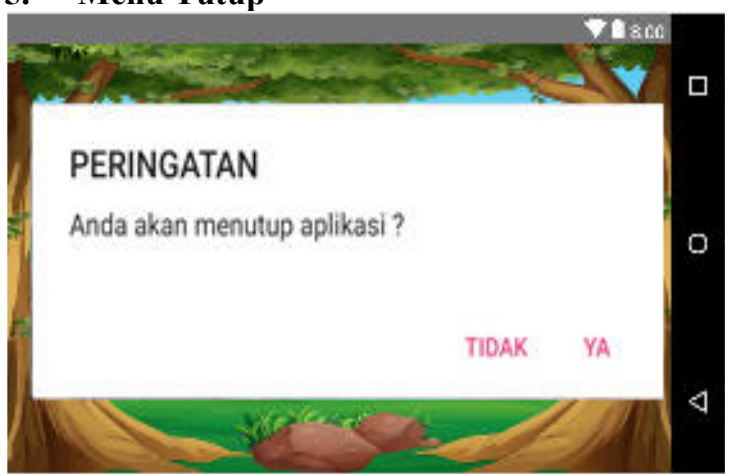

Gambar 10. Tampilan Menu Tutup

Gambar 10 adalah tampilan menu tutup pada saat aplikasi sudah masuk menu tutup, maka akan menampilkan sebuah pertanyaan Apakah Anda Ingin menutup?, jika pengguna menekan tombol tersebut maka aplikasi akan berhenti. Apabila pengguna memilih tombol tidak, maka akan kembali ke menu utama.

perancangan serupa pernah di lakukan oleh peneliti lain adalah dengan Aplikasi Pembelajaran Interaktif Pengenalan Hewan pada Anak Usia Dini [6],dia menggunakan Adobe Flash yang agak sulit untuk di jalan di operasi platform android.

Dalam penulis ini melakukan racangan ulang aplikasi mengenal Nama hewan ke platform android sehingga aplikasi ini nantinya dapat dimainkan di smartphone atau tablet dengan sistem operasi android.

\section{SIMPULAN}

Berdasarkan pembahasan terhadap hasil dari penulisan laporan dan aplikasi yang telah dibuat, kami selaku penulis mendapat kesimpulan yang mungkin diperlukan untuk pengembangan aplikasi pengenalan nama nama hewan. Kesimpulan yang didapat dari aplikasi ini adalah sebagai berikut diantaranya disini kami selaku penulis menyediakan materi pembelajaran dasar meliputi pengenalan nama hewan. Adapun aplikasi pengenalan nama nama hewan ini dapat dioperasikan pada handphone android dengan versi minimal 4.2.2 (kitkat). Aplikasi ini diperuntukan untuk anak usia $2-6$ tahun serta dapat dimainkan oleh satu orang saja. 


\section{DAFTAR PUSTAKA}

[1] A. Arsyad, "Media pembelajaran," media pembelajaran, 2002.

[2] Jazi Eko Istiyanto, Pemrograman Smartphone Menggunakan SDK Android dan Hacking Android. 2013.

[3] D. Darmawan, Pengembangan ELEARNING Teori dan Desain. 2014.

[4] A. Azhar, "Media Pembelajaran," Meedia Pembelajaran, 2008.

[5] P. D. Roger S. Pressman, "Rekayasa Perangkat Lunak - Buku Satu, Pendekatan Praktisi," in Software Engineering: A Practitioner's Approach, Seventh Edition, 2012.

[6] N. Maulida, H. Anra, and H. S. Pratiwi, "Aplikasi Pembelajaran Interaktif Pengenalan Hewan pada Anak Usia Dini," J. Sist. dan Teknol. Inf., 2018. 